\title{
Rising After the Storm: Interweaving Indigenous Philippine Dance and Music and Western Classical Music for Recovery and Wellbeing
}

\section{暴风雨后的崛起 : 交织菲律宾本土舞蹈、音乐和西方古典音乐 以期康复和健康}

\author{
Gina Alfonso \\ Cartwheel Foundation, Philippines
}

\begin{abstract}
Long-term recovery programs for the survivors of typhoon Haiyan - as it struck the Philippines in 2013 - were inevitably characterized by a convergence of Eastern and Western approaches to health and wellness due to the sectors involved in the process. Local community volunteers and local/international non-profit organizations joined forces to offer socio-emotional support to over 100 families of Tagbanua heritage on three islands in the area of Culion, Palawan, Philippines. This paper presents the blending of Eastern and Western perspectives on post-traumatic symptoms, on well-being and on the human condition. The combined spirit of compassion and bayanihan (a Filipino term for togetherness in common effort) shared by the relief workers and the Tagbanua is also described. Narratives about the unexpected discovery of inherent indigenous ways of coping through dance - and a therapeutic encounter that involved a dialogue between Tagbanua and Western classical music - are highlighted as examples of the interweaving of artbased healing practices from the East and West which contributed towards recovery and the restoration of health.
\end{abstract}

Keywords: Psychosocial support, Filipino psychology, Typhoon Haiyan, Philippine indigenous dance, Western classical music.

\section{摘要}

关于曾在2013年袭击菲律宾的台风海燕幸存者的长期康复计划，不可避免地表现为东 西方健康和福祉方法的融合，这是由于该计划涉及了这些内容。当地社区志愿者和当 地/国际非营利组织联合向菲律宾巴拉望和库利昂地区三个岛上的100多个塔格巴努亚土 著家庭提供心理支持。本文介绍了东西方对创伤后症状、健康状况和人类状况影响的观 点，并描述了救援人员和塔格巴努亚人分享共情和Bayanihan（菲律宾语共同和协力之 意 ) 的精神。关于通过舞蹈应对，这种固有的土著方式的意外发现以及涉及塔格巴努亚 与西方古典音乐之间对话的治疗性相遇的叙述突出显示了东西方艺术为基础的针对康复 和福祉的健康治疗实践相互交织的案例。

关键词: 心理社会支持, 菲律宾心理学, 台风海燕, 菲律宾土著舞蹈, 西方古典音乐。 


\section{Introduction}

Global news has been flooded with reports of the threat of war, terror, hurricanes and earthquakes - all putting the entire world in a constant state of hyper-vigilance. Stories of devastation, death and loss have been many - but accounts of survival, courage and the generosity of the human spirit have more than compared in number. Narratives about people coming together to lift each other up - regardless of racial, religious, cultural or economic differences - abound, accompanied by many lessons to share about celebrating diversity and acknowledging the gifts that come with it. Such stories need to be told in order to counter the frantic hyper-alertness to danger which is now making societies ill. The first step towards recovery and peace must be a reassurance that most human hearts, regardless of background, share a common desire for the world's peace and wellbeing.

On November 8, 2013, a category 5 Typhoon Haiyan (or Yolanda) made landfall in the central Philippines causing widespread flooding and landslides affecting 9.7 million people (USAID, 2013). After passing through the central islands, Typhoon Haiyan proceeded west to make landfall in Northern Palawan, Philippines. Three particular islands in the area - project partners of Cartwheel Foundation (CFI), a Philippine non-profit focused on indigenous peoples (IP's) education - were gravely affected. The island villagers' homes and boats were completely devastated. Some forty minutes away by boat from the nearest mainland, was the township of Culion; there, the affected families had no access to any emergency supplies. While assistance for the survivors of Haiyan from multiple international organizations was immediate, aid was directly primarily towards the central provinces affected - namely Samar, Leyte, Ilo-Ilo, and Cebu.

Emergency assistance for Northern Palawan came later and initially originated from the nearest Manila-based Philippine non-profit organizations. CFI was quick to respond on the ground. Five years prior to the arrival of Haiyan, CFI had established a presence in the specific islands of Alulad, Cagait and Chindonan - and in the area of Culion, Palawan - to make culturally relevant education accessible to the people living there. In addition to supplying the more immediate needs for food, shelter, clothing and rebuilding supplies, the same 'first-responder' non-profit organizations, led by CFI, later broadened the scope of their support to include long-term psychosocial services.

This paper explores the inclusion, bridging and blending of Eastern and Western approaches to make psychosocial services accessible to the partner communities of CFI. The dualistic and parallel perspectives (Kim \& Berry, 1993) from a Manila-based team (including Filipino therapists trained in the U.S.), a Filipino volunteer psychosocial support team, and also survivors of Haiyan (residents of the township of Culion), will be presented. In addition, lessons learned about the convergence of Eastern traditional and classical Western music (during the meeting of classically trained musicians from the Julliard School of Music in New York and the Tagbanua survivors) will be discussed.

\section{Definition of Terms}

For the purpose of this paper, the term indigenous, traditional and folk will be used interchangeably to describe an Asian (Eastern) indigenous perspective. Merriam-Webster's 
(1976) definition of indigenous is defined as follows: "native: (1) not introduced directly or indirectly according to historical record or scientific analysis into a particular land, region or environment from the outside, (2) originating or developing or produced naturally in a particular land, region or environment, (3) of, relating to, or designed for natives" (Kim \& Berry, 1993).

References to other non-Asian indigenous (e.g. North American or African) perspectives are cited and identifiable in the bibliography. While indigenous healing practices in these two groups overlap (Asian and non-Asian), the descriptions referred to in this paper are primarily Asian or Eastern and will include non-indigenous perspectives from the same culture, e.g. Filipino psychology (although this is indigenous to the Filipino in general, it is not specific to the pre-colonial heritage of the indigenous peoples [IP's] in the Philippines.) References made to Western psychology or psychosocial approaches to healing primarily reflect concepts from the U.S. definitions of psychology and the social sciences. To distinguish Eastern and Western points of view here although overlapping and complementary - Wilhelm Wundt's two traditions in psychology as science will be used: the natural sciences tradition (West) and the cultural sciences tradition (East) (Kim \& Berry, 1993).

\section{Multicultural Filipinos' Shared Convictions (Panindigan)}

Virgilio G. Enriquez, Father of Filipino psychology, describes the Filipino as one who continues to build and to grow, to fail and to succeed, to evolve and to triumph no matter the challenges. Filipino identity, Enriquez says, is not static, and can be as varied as his background. This is as true today as it was half a century ago. Evident in its rich history with periods occupied by both Spain and the United States, Philippine society and the Filipino psyche are layered with multiple strains of Western influence despite there being an undeniable median between Southeast Asian and Pacific Islander cultures (Apostol, 2010). Sikolohiyang Pilipino (Filpino Psychology) as it is called in Tagalog or Filipino (the Philippine native tongue) is rooted in the history, language, arts, and common experience of the people of Malayo-Polynesian and Asian heritage (Apostol, 2010). The understanding of the Filipino identity is reflected in his conception of selfhood, which is primarily relational (Kim \& Berry, 1993).

Despite the varied backgrounds of Filipinos, Enriquez' take on the Filipino psyche highlights a central, shared panindigan (conviction) that captures the essence of being Filipino: paggalang and pagmalasakit (respect and concern), pag-tulong and pagdamay (helping), pagpuna-sa-kakulangan (understanding limitations), pakikiramdam (sensitivity and regard for others), gaanng-loob (rapport and acceptance) and pakikipagkapwa (sense of fellow being; having regard for the dignity and being of others) (Enriquez, 1977). Enriquez explains, however, that a consciousness of being Filipino does not necessarily imply a valid awareness of the Filipino situation, predicament and social reality (Enriquez, 1977). It does, however, imply an intimate knowledge of his personal experience as an individual Filipino (Enriquez, 1977) which happens through understanding or "knowing" by feeling, sensing and intuiting (Apostol, 2010). This personal experience and knowledge comes to light when he comes in contact with a 
non-Filipino - possibly a visitor in the Philippines - or a native of another country whom the Filipino meets when he travels abroad (Enriquez, 1977). In Asian cultures, the self is a relational self - one that is intensely aware of the social presence of other beings (Kim \& Berry, 1993).

The various groups of Filipinos referred to in this paper will be distinguished by their geography, history and cultural background: IP's from a cultural community of Tagbanua heritage, descendants of the earliest island settlers in the Philippines most likely originating from Borneo; Tagalog Filipinos who were transferred from provinces all over the Philippines to the island of Culion, Palawan, (a former leper colony); and Filipinos of a mixture of backgrounds from the urban capital of Manila. All these groups were quick to respond to the plight of the Tagbanua after Haiyan, and had varied yet similar perspectives on psychosocial support and healing. They were later joined by a group of musicians from the United States who shared many Filipino views on the value of community and relationships in health and recovery.

\section{Helping (Pagdamay)}

The Culion local government and the Jesuit Mission CFI - another non-profit organization including Parish volunteers and public school teachers - were the first responders to the three affected islands. Soon after the storm, the CFI team, together with its community teachers and residents of Culion who run the schools in the villages, initiated a longer-term recovery effort called Project RISE. This was a program which would span over three years post-Haiyan, and it evolved in consultation with chief elders of the Tagbanua communities. The three phases were identified as follows: (1) to address immediate psychosocial and rebuilding needs, (2) to strengthen the Tagbanua communities' disaster resilience via continued psychosocial support through the expressive arts and sustainable livelihood development programs, (3) to integrate these sustainable livelihood activities into the islanders' life ways and ensure the security of their basic needs (Ortiz-Luis \& Dolatre, 2014).

During the first phase of recovery, the goal was to establish accessible, community-based psychosocial support for the survivors. This began with an initial visit by CFI a month after the storm. Soon afterwards, volunteer psychosocial support workers including the Culion-based parish volunteers and government and CFI teachers - gathered for a psychosocial support expressive arts based training program to prepare for a kamustahan and a visit to the three affected islands. (Kamusta translates as "How are you?" A Kamustahan is a gathering to learn how participants are doing). This direct application of pakiramdam and pagmamalasakit was meant to help determine how best the volunteer psychosocial support team might offer socio-emotional support to the survivors; this was an implicit socio-emotional assessment (Oulanova \& Moodley, 2010) or needs assessment.

The volunteer psychosocial support team prepared questions for their visit to the three Palawan islands. Conversations during the kamustahan were casual but respectful (paggalang). In line with the idea of kapwa (fellow being; core concept of pakikipagkapwa), the volunteer support team avoided assuming an expert role, but instead followed 
the lead of the community (Oulanova \& Moodley, 2010). If the situation called for it, the volunteer team was prepared to engage in play, expressive arts and mindfulness-based activities. It was agreed that this approach was relevant to the indigenous culture of the Tagbanua. The hope was to learn about the ways in which the people were coping, and to offer other helpful ways to alleviate their post-Haiyan anxieties and stress.

Three boats - each with a team of psychosocial support volunteers - traveled to one island each to do a kamustahan house-to-house. Upon arrival in the communities, a courtesy visit was made to the Tagbanua village elders to request permission to be on the islands and to begin the home visits. The teams on each island captured multiple stories shared by the Tagbanua families. One group recounted the response of a Tagbanua father who lifelessly shrugged his shoulders upon their inquiry about what he had been preoccupied with since the storm. He replied, flatly:

"Before Yolanda arrived, life was hard for us. Now, life is still hard. There isn't any difference, storm or no storm."

This illustration of this dualism (Kim \& Berry, 1993) in developing countries gave the Culion-based psychosocial support team reason for pause. Residing in the mainland gave them better access to emergency support and access to basic necessities including electricity, running water, health care, education and other services. This, their first visit to neighboring islands which were separated from the mainland by a thirty to forty-minute boat ride, underscored the stark difference between their lifestyle and that of the Tagbanua who lived with no electricity or access to running water and were focused primarily on the daily need to provide for their families through gathering seaweed, sea cucumbers and fish. These essential activities were abruptly halted by Haiyan's destruction of their boats.

One common habit of the Tagbanua women on the islands was to gather by the shore, squatting side by side. During the community visit, some volunteers (including the EXA therapist - author) sat with them. They seemed lethargic, and sad. After exchanging greetings with them, the volunteer EXA therapist inquired about what they found themselves preoccupied with since the storm. They replied, "Nothing much." They went on to express their frustration about not having had coffee that day. Coffee made everything better for them; it gave them energy and joy. Due to depleted resources, however, they had been unable - for some weeks - to pick up their coffee supply from Culion. The volunteer therapist noted this and then respectfully took the opportunity to further inquire what else helped them cope and feel better. One of the ladies, a village elder in the circle, immediately sprang to her feet exclaiming, with eyes lit up, "Ang Suring!" She then began to demonstrate a gentle dance as she lifted her hands towards the sky and gracefully moved across the shore. With her silver hair dancing in the wind, she was a vision to behold. The volunteer later learned that this was their tribal courtship dance. The other volunteers joined the Tagbanua leader who seemed delighted by their attempt to mirror her movements.

Later, the village elder spoke of how the community gathered every Saturday to dance. As a leader, one of her roles was to care for the wellbeing of the whole community. 
Grateful that their lives had been spared, they danced in celebration. During the storm, one child was lost in the initial sea surge and almost drowned, but the entire community joined forces to find him and he was saved. Since then, they designated a flat area on top of a hill on the island as their Saturday gathering place to give thanks. They fenced it with bamboo to mark it off. The elder expressed how coming together and dancing had helped them to cope and to momentarily forget about the fright they had experienced during Haiyan.

After thanking the affected Tagbanua families, the psychosocial support teams returned to Culion to exchange notes on their visits. Plans were discussed and roles identified for the next phases of Project RISE. Commitments were made for follow-up visits.

\section{Togetherness in common effort, sensitivity and regard for the dignity of others (Bayanihan, Pakikiramdam at Pakikipagkapwa)}

Bayanihan, as defined by Oxford dictionary, is derived from the Tagalog (another term for Filipino, referring to the official Philippine language) term bayani (a hero; to work unpaid), and refers to as a system of mutual assistance in which the members of a community work together to accomplish a difficult task. This palpable and energizing spirit, alive among the Project RISE volunteers, is reflective of a regional perspective on healing which emphasizes connectivity, togetherness, and presence as an essential part of recovery. Many of the Tagbanua families expressed both surprise and appreciation that a group would travel such a distance out of concern for their condition after the storm. Historically, Tagbanuas are socially isolated. Unfortunately, they are still occasionally labelled (rather condescendingly by less-aware communities in the mainstream) as 'natives' - a term sometimes used with derogatory underpinnings, referring to a way of life perceived as 'backward.' "We appreciate how you made us feel valued, worthy of a visit," the Tagbanua expressed in their mother tongue. "Your presence lifted our spirits." The Tagbanua are quick to notice traces of discrimination against their group and are highly sensitive to spoken and unspoken expressions of acceptance and mutual respect. In her book Presence and Process, Sally Atkins emphasizes the importance of presence and attunement in a helping relationship, particularly in the use of expressive arts therapies (Eberhart \& Atkins, 2014). This first visit of the psychosocial support team established a good beginning point for succeeding encounters with the Tagbanua, which paved the way for the deepening of relationships of trust, and the future, respectful integration of the expressive arts and mindfulness activities.

Pakikiramdam was also evident in the way the psychosocial support team prepared, formulated questions, and paid respects to the chief elders before their home visits. This demonstrated both cultural sensitivity and a basic respect for differences. The volunteers expressed a deep sense of appreciation for the opportunity to know and connect with island neighbors they hadn't previously met, and whose life ways were unique from theirs. Previously held impressions of the Tagbanua and townsfolk had created barriers that prevented each group from coming to know and understand each other. 
The Philippines is a highly stratified and hierarchical society with social acceptance driving an immense amount of Filipino behavior (Lynch, 1973). While it wasn't evident in this context among those in the psychosocial support team and the island villagers, it is important to be aware of how - on other occasions - smooth relations (or pakikiramdam) could, in reality, be the avoidance of open conflict; it functions to suppress underlying tensions and to maintain the status quo (Kim \& Berry, 1993).

The sense of pakikipagkapwa is best reflected in the volunteer creed which the psychosocial support team composed for their community visits and their long-term work beyond:

\section{2}

"As a volunteer, I will wholeheartedly serve those in need. I will be ready and disciplined, and available at any moment. I will serve with sincerity and humility and will do everything in my capacity to stay thoughtful, understanding and faithful to God, my neighbor and country without expecting anything in return."

\section{East-West Perspectives on Depression and Healing}

In the 1960's, references to mental illness in the Philippines stated that its most frequent manifestation was somatization (Shakman, 1969). The ill feelings reported by the Tagbanua families after Haiyan were somatic and psychological - congruent with typical Western post-traumatic symptoms. They were summarized by the volunteers as: trembling and nervousness triggered by strong winds; the fear of another storm coming; intrusive memories of being in the water at night (which is when the storm struck) with parts of their homes floating around them; anxiety and sadness. Children were reported to have had nightmares as well as manifesting an intense fear of the dark. Many of the male villagers' expressed concerns were more practical. Most were frustrated about the lack of aid for their boats and homes.

Another IP group from Southern Philippines, the Maranao, describes depression as manifested through glazed empty looks, a lack of facial expression and down-turned eyes (Shakman, 1969). Symptoms included fatigue, insomnia and remarks of guilt and punishment. The Culion volunteer team observed these among the Tagbanua. While many of these align with universal symptoms of depression, the Maranao also believe depression is caused by the introjection of Satan (Shakman, 1969) which connects illness to the spiritual realm and may offer some explanation for the guilt the Tagbanua expressed after the storm. Some members of the community believed their god had sent Haiyan as a punishment.

Regardless of geography, cultural origin or religious beliefs, traditional Asian cultures share healing concepts that reflect both their world view and their beliefs about human relationships and connections with a supreme being (Wing, 1998). The Cartesian body-mind division seems to be an absent phenomenon in the philosophy of traditional indigenous healing (Moodley, 2005). In Asian indigenous cultures, healing and spirituality are tightly interwoven and the use of traditional methods for healing is effective as long as people have faith in the system they own (Moodley, 2005). 


\section{Traditional Eastern and Contemporary Western Perspectives on Healing through Dance}

The psychosocial support team from Culion was particularly impressed by the strength of the Tagbanua heritage and traditions that play a natural role in their recovery from trauma or stress. To witness the capacity of traditional societies such as the Tagbanua to overcome the damage brought about by natural hazards (Gaillard, 2006) was inspiring, humbling and educational. Without necessarily consciously or purposely connecting their suring dance to their own post-disaster symptoms, the Tagbanua's inherent capacity to heal taught volunteers that their roles as psychosocial support workers were primarily to offer presence and not much more. Any expressive arts activities to be shared later with the survivors would be a bonus.

The Tagbanua's relationship with the spirit world is the basis for their rituals, celebrations and dances ("Tagbanua Tribe," n.d.). With indigenous cultures, and select belief systems from both the east and west, healing and spirituality are one (Wing, 1998). The suring was their form of dance therapy; when the Tagbanua dance, they become the dance. Even without music, their movements suggest a kind of inner music (Dissanayake, 1995).

The roots of dance therapy as practiced in the West have ancient underpinnings (Serlin, 1993). Modern dance therapists practice with the understanding that healing approaches are enriched with echoes of ancient images and practices (Serlin, 1993). Earliest religious or spiritual experiences were physical, where the deity was felt to enter and transform the person (Serlin, 1993). In his book on dances, the early Greek writer Lucien noted how all mystery inductions were associated with dance, and that Orpheus prescribed those being introduced to the mysteries to be received by dancing (Serlin, p. 66). Perhaps suring could be likened to an induction to a new life. As a courtship dance, it signifies a transition from one life stage to another. It also agrees with other indigenous groups' worldview of dance as a conduit of both individual and community healing where conceptualizations of illness and health integrate social, spiritual, physical and mental realms (Monteiro \& Wall, 2011). The Tagbanua from these islands displayed an intuitive, tacit knowledge of the healing power of dance. The relief they experience from the suring is succinctly validated by Hanna (2007), who enumerates how dance conditions its participants to moderate, eliminate or avoid tension, chronic fatigue and other disabling conditions that result from the effect of stress. Dance helps one to gain control and heal by 1) possession by the spiritual in dance, 2) mastery of movement 3) escape or diversion from stress and pain through change in emotion, states of consciousness and/or physical capability and 4) confronting stressors to work through ways of handling their effects (Hanna, 2007).

\section{A Dialogue between Traditional Tagbanua and Western Classical Music}

Soon after the first visit of the newly formed psychosocial support team, William Harvey reached out to CFI to offer support to the Tagbanua communities affected by Haiyan. Harvey is the founder of Cultures in Harmony $(\mathrm{CiH})$ - an international 
non-profit organisation that started as a response to the 911 terrorist attacks in New York City. CiH had visited the Philippines years before to work with other partner communities of CFI. This previously established relationship allowed for quick, easy collaboration and coordination despite the geographic distance between the two groups. Harvey sent his colleagues (also New York-based classical musicians from Julliard) with the clear objective to "make music" with the Tagbanua survivors of Haiyan. The project was named "Structures of Culture, Structures of Hope." This CiH-CFI collaboration became part of Project RISE's healing, recovery and rebuilding efforts (Ortiz-Luis \& Dolatre, 2014). Chief Tagbanua elders and CFI knew the CiH visit would be an opportunity for survivors to pause and refocus away from the storm-induced stress. Music was deeply integrated into the lives of their ancestors, for all occasions, for every phase of life, from birth to death (Tiongson, 1991), and was a welcome source of relief and healing.

In August 2014, four CiH musicians flew from the United States to visit the islands in order to hold cultural and musical exchange workshops and performances. For five days, Julliard-trained classical musicians made music with a select group of Tagbanua instrumentalists. The opportunity for learning about each other's music was deep and meaningful; interactions were rich and full of energy. Introductions began with each of the groups performing a traditional piece from their own communities - the Tagbanua sang the Tablay and demonstrated their courtship dance Suring. CiH musicians in turn played Ashokan Farewell - an example of an instrumental American folk song - and Fugue from K.404A: Adagio-Vivace by Mozart as an example of classical European music (Ortiz-Luis \& Dolatre, 2014).

What evolved from this exchange was a process of creating new arrangements - an experience fueled by the group's newfound camaraderie. The interweaving of melodies, for example, would begin with a Tagbanua flutist playing his tune. This, in turn, would be followed by the $\mathrm{CiH}$ musician responding with his viola as he gave a rendition of the same tune. The process was then repeated with the $\mathrm{CiH}$ musician playing first. The $\mathrm{CiH}$ musicians also shared their process for learning a new tune: listening, recording notes and playing. The recording of the notes, they explained, created a universal language that could be played by all (Velhagen, 2014).

Nurturing a free and open learning environment, the Tagbanua also took turns sharing stories about how they crafted their instruments using varied materials (wood, metal, string), sharing inspiration for their creations and demonstrating the use of each piece. Each group experimented with the others' instruments - the Tagbanua playing on the Western violin, viola, cello, and French horn, and the $\mathrm{CiH}$ musicians creating music with the indigenous tambol (drums), flauta (flute), and yuke (ukulele). The connecting of cultures through stories and songs inspired the Tagbanua to recommit to keeping their indigenous music alive (Ortiz-Luis \& Dolatre, 2014).

The workshops became exchanges transcending language and cultural barriers, with $\mathrm{CiH}$ and Tagbanua musicians performing alongside each other in a series of interactive musical concerts. They toured around the Haiyan-affected islands and the main townships, including Culion. They even serenaded the former patients at the Leprosarium and General Hospital. Audiences, who were all actively engaged in the combined 
Western and Tagbanua concerts, learned about each musical tradition (Ortiz-Luis \& Dolatre, 2014).

One elder musician from the Tagbanua community expressed his joy. "It was a beautiful and joyous five days because we were celebrating together." Another elder voiced his feelings and happiness about "spending time with our brothers and sisters from another country; it was enjoyable to learn together, to exchange stories about our culture, roots and ancestors." He continued to stress the importance of a lifelong commitment to encourage these opportunities to share stories and celebrate culture, which they wish to impart to others beyond their communities. Another guitarist from the Tagbanua community intimated, "I am so thankful to the visitors from other places who have come to share our culture with us. I realized I should be proud of my traditions, and I want to pass them on" (Velhagen, 2014).

The collaboration culminated in a concert entitled "Cultures in Harmony: Building Structures of Hope with Filipino Indigenous Communities" where the four $\mathrm{CiH}$ musicians performed with members of the Manila Symphony Orchestra (MSO) and MSO Junior. Both Western classical pieces and Filipino folk songs were presented. One of the highlights of the concert was the grand finale where $\mathrm{CiH}, \mathrm{MSO}$ and MSO Junior jointly performed the Tagbanua Paalam (Farewell) Song which had been arranged for string orchestra by $\mathrm{CiH}$ musicians (Ortiz-Luis \& Dolatre, 2014).

\section{Asian Indigenous Music and Music Making As Therapy}

The Tagbanua rituals of song and dance exist also to placate or gain the favor of their spirits and gods. Their supreme being (or god) Mangindusa is said to sit up in the sky with his feet dangling towards the islands ("Tagbanua Tribe," n.d.). Celebrating with music in collaboration with $\mathrm{CiH}$ was a transformative experience. And the Tagbanua, through the pakikiramay of the $\mathrm{CiH}$ musicians were able to appease the angry Mangindusa who, for some, was acknowledged as being responsible for Haiyan.

One of the most powerful features of classical music is the way it seems to teeter on the edge of speech (Kramer, 2007). It can be challenging - particularly in the context of the $\mathrm{CiH}$ project - to know what each composition almost says (Kramer, 2007). But one can harmonize words or various types of music with classical sounds in ways that can be healing. (Maybe even in ways that can speak to gods!) Its power was recognised as being both magical and therapeutic. Beyond the spiritual, the bridging of classical and indigenous music seems to have had psychotherapeutic, rehabilitative, preventive and communicative functions (Shakerimova et al., 2016). The main influence for both was rendered on higher levels of the human psyche, matching the current ways in which music therapy is recognised as being rehabilitative (Shakerimova et al., 2016). What transpired between the exchange of $\mathrm{CiH}$ and the Tagbanua musicians may be likened to community music therapy that challenges the biomedical model of illness. Community music therapy uses an approach to the music in therapy that is sensitive to cultures and contexts - speaking of more acts of solidarity and social change (Ansdell \& Pavlicevic, 2004). In this case, the acts of solidarity became a spiritual experience and led to the breaking of language and cultural barriers. 


\section{Shared Values and Interwoven Concepts of Healing}

Evident in this post-Haiyan encounter with the Tagbanua were many interwoven and blended Eastern and Western concepts of healing. Dancing the suring in the community and creating blended Tagbanua and Western classical music were living illustrations of harmony. The $\mathrm{CiH}$ musicians - recognised as a healing, harmonious presence - were perceived as kapwa (fellow beings) by the Tagbanua, implying a recognition of shared identity through the creation of music. Together they created a new language, dismissing the idea that the $\mathrm{CiH}$ musicians as US Citizens are 'outsiders' (ibang - tao, opposite of kapwa). In addition, the Tagbanua shared the more universal view that harmony consisted of taking life for what it was rather than fighting against the principles of nature (Wing, 1998), which aligned with concepts of acceptance, serenity and a balance between distress and elation.

The Tagbanua also believed in the mind-body connection. Simplified variations of yoga and tapping - including arts-based psychosocial support activities such as painting, sculpture, drama, storytelling, play, singing and versions of dancing from other indigenous groups - were shared with them in order to help relieve their neural systems of the stress response. They particularly liked tapping to release tension and to relax their overburdened bodies. The positive physiological impact of the patterned repetitive movements of tapping, dance and song created a set of somatosensory experiences that lead to a neurobiological experience, influencing cortical, limbic, diencephalic, and brain systems (Malchiodi \& Perry, 2015).

The neurobiological impact of positive relationships on the vagal nerve and the management of stress and trauma symptoms also validated (Van der Kolk, 2015) the importance of positive family relationships and of connectedness in healing. Dance and song for the Tagbanua offered an intensely relational experience with families, clans or groups from other cultures they considered as kapwa. During succeeding visits to the islands, the sense of family and community involvement among all the groups involved in supporting the health and wellbeing of the survivors was significantly strengthened. The Tagbanua communities in this case expressed feeling deeply reassured by the knowledge they were not alone.

The known beliefs, rituals and healing practices for loss and trauma that remain from aboriginal cultures reveal remarkable principles (Malchiodi \& Perry, 2015). As evident in the living traditions of the Tagbanua, the practices emerge because they work; people feel and function better, and the core elements of the healing process are reinforced and passed on (Malchiodi \& Perry, 2015).

\section{Conclusion}

It is quite evident that the convergence of identities, cultures and approaches to healing from the almost indistinguishable Eastern indigenous and Western practices impacted positively on all those involved in Project RISE post-Haiyan. The Tagbanua survivors, even in their isolated villages, realized they weren't alone. With every visit to their islands, they were enlivened by an expressed interest in their traditional dances and rituals. Similarly, the psychosocial support team was awakened and humbled by the 
realities of life of the Tagbanua and the immense joy and gratitude shared by all in the islands. As they gained a deeper appreciation of their connections with each other and with their newfound neighbors, they also expressed appreciation for being valued for their generosity, despite being Haiyan survivors themselves. Finally, the $\mathrm{CiH}$ Musicians felt welcomed, valued and appreciated, making the trip to Palawan more than worthwhile. The musicians expressed how sharing a common musical language with the Tagbanua, exchanging stories and learning indigenous dances and songs was deeply transformational.

Harmonizing Tagbanua and Western classical music, including dancing the Suring, brought about a real sense of community, acceptance and generosity - and a deep respect for all differences. These shared values - emerging through a mixture of art forms, rituals and tradition - validated the equality, significance and importance of all present in each gathering. A common appreciation for beauty and healing resulted in the natural marriage of "knowing by feeling" (Filipino intuition) and "knowing by making" (poiesis), producing art which played an instrumental role in creating a healing space - one that could effortlessly hold multicultural traditions and perspectives and bring life to all.

This strong sense of identity in both cultures and approaches is essential to healing. While the presence of divergent cultures may sometimes pose a threat to an individual or to community identity as people come together, each person's humanity and vulnerability begins to uncover shared values and an inherent common need to connect particularly in difficult times. The value and love for art of old and new, north and south, east and west, makes such a coming together with openness and respect possible. The sharing of dances, the harmonizing of music, the exchanging of stories, and the appreciation and interweaving of our distinct (but not so disparate cultures) are all living reminders that, in the most trying of times, we can count on each other and will always find (sometimes in the most unexpected of places) reasons to hope and celebrate.

\section{About the author}

Alfonso, M.R., M.S.Ed., ATR-BC, LCPAT. Founder, Cartwheel Foundation, Inc. Director, MAGIS Creative Spaces. Lead Global Trainer/Consultant, Save the Children, Intl'l. Research field: the expressive arts for healing and education in disaster contexts and indigenous communities.

\section{References}

Ansdell, G., \& Pavlicevic, M. (Eds.). (2004). Community music therapy. London: Jessica Kingsley.

Apostol, V. M. (2010). Way of the ancient healer: Sacred teachings from the Philippine ancestral traditions. North Atlantic Books.

Dissanayake, E. (1995). Homo aestheticus: Where art comes from and why. Seattle and London: University of Washington Press.

Eberhart, H., \& Atkins, S. (2014). Presence and process in expressive arts work: At the edge of wonder. London: Jessica Kingsley.

Enriquez, V. (1977). Filipino psychology in the third world. Philippine Journal of Psychology, 10(1), 3-18.

Gaillard, J. C. (2006). Traditional societies in the face of natural hazards: The 1991 Mt. Pinatubo eruption and the Aetas of the Philippines. International Journal of Mass Emergencies and Disasters, 24(1), 5-43. 
Hanna, J. L. (2007). The power of dance: Health and healing. The Journal of Alternative and Complementary Medicine, 1(4), 323-331.

Kim, U., \& Berry, J. W. (Eds.). (1993). Indigenous psychologies. California: Sage Publications, Inc.

Kramer, L. (2007). Why classical music still matters. California: University of California Press.

Lynch, F. (1973). Social acceptance reconsidered. In F. Lunch and A. de Guzman II (Eds.). Four readings on Philippine values (4th ed., pp. 1-68). Quezon City: Ateneo de Manila University Press.

Malchiodi, C., \& Perry, B. (2015). Creative interventions with traumatized children (2nd ed.). New York and London: Guildford Press.

Monteiro, N. M., \& Wall, D. J. (2011). African dance as healing modality throughout the diaspora: The use of ritual and movement to work through trauma. The Journal of Pan African Studies, 4(6).

Moodley, R. (2005). Integrating traditional healing practices into counseling and psychotherapy. USA: Sage Publicaions, Inc.

Ortiz-Luis, M. J. P., \& Dolatre, M. R. (2014). "Structures of Culture, Structures of Hope" A Collaboration between Cartwheel Foundation, Inc., and Cultures in Harmony for the Tagbanua Indigenous People of Northern Palawan (Project Report) (pp. 1-7). Manila, Philippines: Cartwheel Foundation, Inc.

Oulanova, O., \& Moodley, R. (2010). Canadian Journal of Counselling and Psychology, 44(4), 346-362.

Serlin, I. (1993). Root images of healing in dance therapy. American Journal of Dance Therapy, 15(2), $65-76$.

Shakerimova, Z.S., Nussupova, A. S., Burambaeva, M. N., Yermanov, Z. R., Emreyeva, A. E., \& Janseitova, S. S. (2016). Psychotherapeutic function of the Kazakh traditional music. International Journal of Environmental and Science Education, 11(17), 10321-10335.

Shakman, R. (1969). Indigenous healing of mental illness in the Philippines. International Journal of Social Psychiatry, 15(3), 279-287.

Tagbanua Tribe. (n.d.). Retrieved from https://www.scribd.com/document/256543026/Tagbanua-Tribe\#

Tiongson, N. (Ed.). (1991). Tuklas sining: Essays on the Philippine arts. Cultural Center of the Philippines.

USAID. (2013, November 11). Typhoon Haiyan/Yolanda Fact Sheet \#1.

Van der Kolk, B. (2015). The body keeps the score: Brain, mind and body in the healing of trauma. New York: Penguin Books.

Velhagen, K. (2014). The Cultures in Harmony - Tagbanua Connection: A Joyous Experience of Coming Together. Culion, Palawan: Magis Creative Spaces. Retrieved from http://cartwheelfoundation. org/2014/08/29/the-cultures-in-harmony-tagbanua-cultural-exchange-a-joyful-affair-of-coming-together

Wing, D.M. (1998). A comparison of traditional folk healing concepts with contemporary healing concepts. Journal of Community Health Nursing, 15(3), 143-154. 